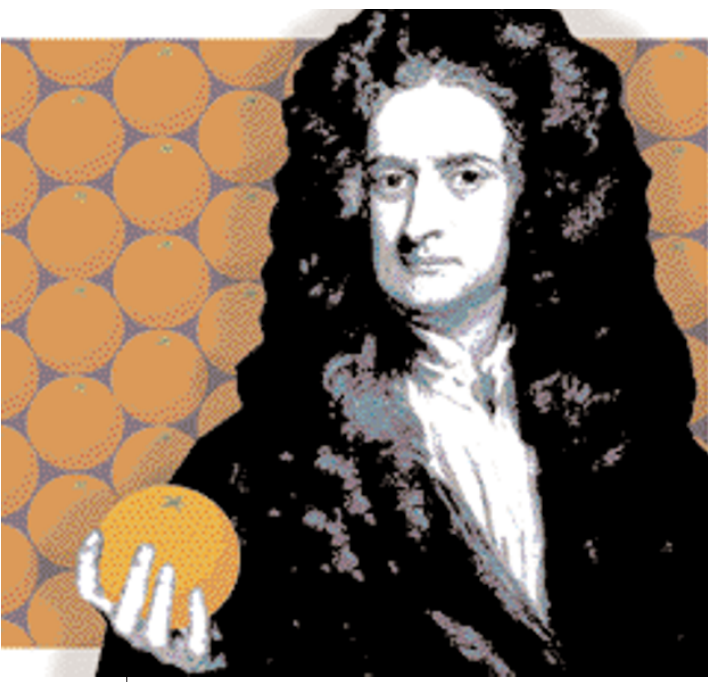

University of Michigan, following an approach developed in the 1950s by the Hungarian mathematician Lázlo Fejes Tóth. Hales showed that it was possible to determine the maximum packing efficiency by analysing a cluster of just 50 spheres. Each sphere has a position in three-dimensional space, so the packing efficiency depends on an equation containing 150 variables. Maximize the equation and you have the maximum packing efficiency, although this is not a trivial problem.

Hales and his graduate student Samuel Ferguson maximized the equation, thanks to some clever mathematical short-cuts and a tremendous computing effort which used a program that relied on three gigabytes of storage. The fact that Hales's proof relies so much on a computer gives rise to one of the most interesting aspects of Casti's book, namely the validity of computer proof.

In fact, although each chapter is about a particular problem, these problems are used to convey broader ideas about the nature of mathematics in general, its motivation and objectives, its culture and rules. Over the past 25 years, the use of computers has changed the nature of mathematics, solving some previously intractable problems, but sowing discord within the mathematical community.

For example, Casti writes about the fourcolour problem, which was also solved with the aid of a computer. After Kenneth Appel and Wolfgang Haken proved it in 1976, their lectures were sometimes met with hostility from their colleagues and some professors barred their graduate students from talking to the notorious duo because this was a computer proof, not a traditional proof. A rumour began to spread that there was a bug in the program, but no bug was ever found. In fact, it was the hand-generated part of the proof that contained errors, none of which turned out to be serious.

Casti explains that a good proof should satisfy three criteria. First, it should be convincing - in other words, mathematicians should believe it when they see it. Second, it should be formalizable, which means it can be incorporated within an established logical framework. Third, it should be surveyable, or capable of being understood, studied, communicated and verified by rational analysis. However, a computer proof fails to satisfy the third requirement, at least in any traditional sense. In the past, mathematicians could work through a proof line by line and explain it to one another. In a computer proof, the broad approach can be checked, but the detailed calculations are embedded within computer code and can be performed only by a microprocessor. The proof, to some extent, has to be taken on trust.

For readers who are particularly inspired by Mathematical Mountaintops and who have some spare time, Casti's final chapter briefly discusses the unsolved Clay Institute problems. Last year, the Clay Mathematics Institute held a press conference and identified seven problems that were crucial to mathematics in the new millennium. This resonates with German mathematician David Hilbert's list of outstanding problems announced in 1900. Whoever solves any of the Clay problems will win a prize of $\$ 1$ million. But more importantly, they will earn a place in mathematical history and perhaps their own chapter in a subsequent edition of Mathematical Mountaintops.

Simon Singh is a science journalist and broadcaster based in London. He is author of The Code Book: The Secret History of Codes \& Code-Breaking (Fourth Estate) and Fermat's Last Theorem: The Quest to Solve the World's Greatest

Mathematical Problem (Fourth Estate).

\section{Is anyone out there listening?}

\section{The World According to Pimm: A Scientist Audits the Earth} by Stuart Pimm

McGraw-Hill: 2001. 304 pp. £18.99, \$24.95

Harold Mooney

Those who study global change are well versed in the sobering statistics of the enormous impact of humans on the Earth - the dramatic change in the chemistry of the atmosphere, the massive alteration of the surface of the land, the diversion and despoiling of a large fraction of the available fresh water, the depletion of ocean fisheries, the homogenization of the Earth's biota and the extirpation of large numbers of species. These scientists share a sense of frustration, however, about the fact that the general public and policy-makers are not grasping the significance of these changes nor acting to alter these trajectories for the well-being of future generations. In The World According to Pimm, Stuart Pimm is attempting to enlarge the army of scientists working on these issues and to engage the public in the dialogue about what is happening to the biotic resources of the Earth and how we need to change our trajectory of development in order to build a sustainable world.

To accomplish his task, Pimm has written an engaging and important book. He might well have called it "The World According to Peter, Paul and Pauly as viewed by Pimm", as the bulk of the book is devoted to an analysis of studies involving Peter Vitousek, Paul Ehrlich and Daniel Pauly. The book takes on a bold challenge - an accounting of the productive capacity of both the land and of the oceans and how humans have modified it. Pimm then documents the extent to which humans are utilizing the available fresh water and, finally, the impact of humans on the biodiversity of the Earth. He uses very simple mathematics and language to drive home the point that humans have very substantially modified the Earth's biotic resources.

The first part of the book is based on the dramatic retelling of the story first published by Vitousek and colleagues in 1986 in BioScience, in which they calculated that humans already use $40 \%$ of the primary productivity of the land. That is a sobering figure in view of the projections of growth of the human population during this century. There was some difficulty in getting this penetrating study published, but once it was, it was used widely. For quite a while it was impossible to go to a meeting related to the environment where the statistics of this paper were not used in the opening address. Subsequent attempts to check and recalculate the numbers, as Pimm has done, have borne out the original thesis. Pimm's recalculations are engaging; he does a very good job of making sure that the general reader can clearly understand the basis for these estimates of human use of the biosphere.

The second part of the book deals with human use of the Earth's water resources and builds on work by Ehrlich and his colleagues Sandra Postel and Gretchen Daily. They have shown that humans are using a sixth of the total estimated runoff ( $50 \%$ of that available), and in doing so have drastically altered the Earth's rivers - its plumbing system especially in the Northern Hemisphere.

The work of Vitousek and colleagues inspired Pauly and a colleague to do a similar

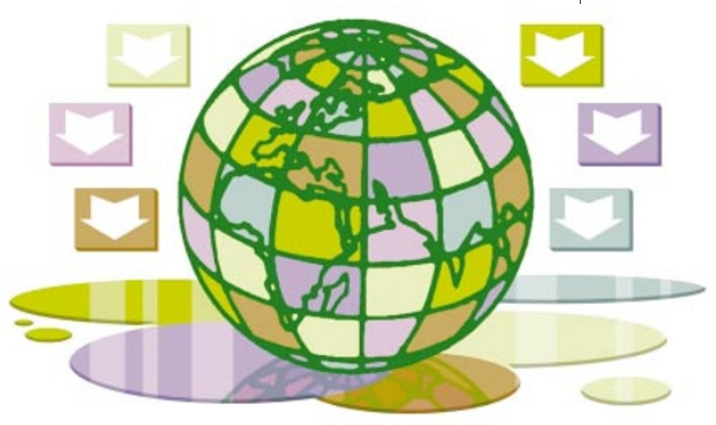


study of the human use of the oceans. They estimated that a third of the oceans' production goes to support human fisheries another stunning number in view of the fact that, not too long ago, the ocean fisheries were considered to be inexhaustible. Large numbers of fisheries are now depleted or endangered. We are clearly at the limits of ocean exploitation. Further, as Pauly and others have shown, we are now "fishing down the food chain", as the large predatory fish have been depleted.

Pimm concludes his book with a sobering analysis of species losses, his speciality. He ends his analysis with a plea for the preservation of those areas of the world that are particularly rich in species, the so-called 'hot spots'. He claims that we do have the means at hand to "defy nature's end" by purchasing and protecting examples of these areas.

In recent years the international scientific community has made an enormous effort to carefully document, through the International Panel on Climate Change, the impact of humans on the Earth's climatic system. The panel has concluded that human action is indeed altering the climate of the Earth with profound consequences for the way we will live our lives. Pimm does not deal with the consequences of these changes, nor with the escalating disruptions due to the biological homogenization of the Earth's biota. He purposely omitted considering future changes and concentrated on what we know now and for certain. Putting where we are today together with what the future most probably holds for the biotic systems on which we depend certainly gives cause for concern. Let's hope that Pimm's book will educate more of us on what the stakes are and why we need to move urgently towards a more sustainable use of our resources than we are seeing today.

Harold Mooney is in the Department of

Biological Sciences, Stanford University,

Stanford, California 94305, USA.

\section{Discourse and discord}

Reconciling Science and Religion: The Debate in Early Twentieth Century Britain

Peter J. Bowler

University of Chicago Press: 2001. 496 pp.

$\$ 40, £ 24$

Rebuilding the Matrix: Science and Faith in the 21st Century Denis Alexander

Lion Publishing: 2001. 544 pp. $£ 20$

\section{Geoffrey Cantor}

These timely books form part of the rapidly expanding body of literature on the interrelations between science and religion.
Bowler, an historian of science who disavows any religious convictions, has addressed a significant lacuna in existing scholarship. Whereas much has been written on the Victorian controversies, often focusing on the scientific naturalism and materialism spearheaded by Thomas Henry Huxley and John Tyndall, little attention has been paid to the opening decades of the twentieth century. The Scopes trial of 1925, which considered whether the state of Tennessee could prosecute John Scopes for teaching the theory of evolution in a public-school science class, is the best-known event of this period. But it had little impact on British writers, who inherited a very different set of religious and social assumptions compared with their American counterparts.

Bowler's main contention is that, during the early twentieth century, discussion of science-religion issues in Britain was dominated by reactions against Victorian naturalism. With agnosticism and materialism considered as passé, many scientists, theologians and popular writers sought a new rapprochement between science and religion. Although a few atheists, such as E. Ray Lankester and Arthur Keith, continued the assault on Christianity, they were considerably outnumbered by those who advocated some form of synthesis.

Yet there was no consensus on how this synthesis should be achieved. Responses ranged from Oliver Lodge's advocacy of spiritualism, which linked the worlds of matter and spirit, to Arthur Eddington's enthusiastic embrace of the new physics in 1927 which, he claimed, only then made religion "possible for a reasonable scientific man". Whereas Bishop Ernest Barnes advocated an effervescent mixing of science with progressivist, evangelical Christianity, churchmen of a more conservative stripe, such as Charles Gore, sought a reconciliation that preserved traditional Christian doctrines.

One of the great strengths of Bowler's book is that it demonstrates the richness of science-religion discourse during this period and provides a helpful map of the terrain. Not only does Bowler discuss the more eminent scientists and theologians, whose positions have previously been analysed, but he sheds considerable light on several lesserknown figures. He also shows that issues of science and religion were subject to comment and controversy far beyond both professional communities. The public, for example, encountered these issues in newspapers, in the periodical press and in books aimed at a wide readership. Thus, authors as diverse as H. G. Wells, G. K. Chesterton and Bertrand Russell are included in Bowler's analysis. Given the considerable range of commentators discussed, it is not surprising that Bowler has paid less attention than he might to the broader social and political movements of the period that impinged on

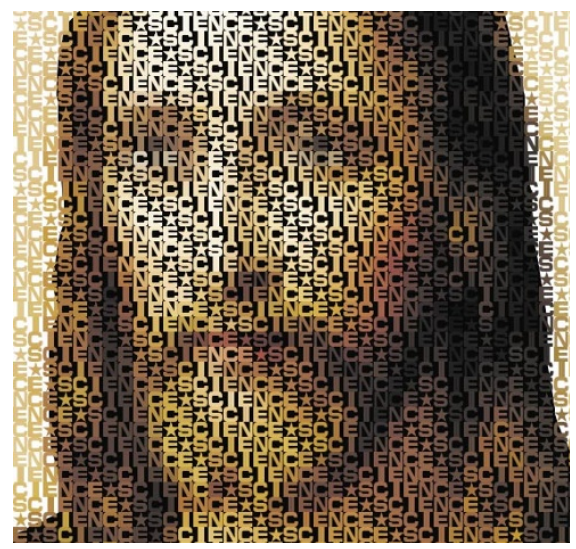

the religious and scientific life of Britain.

The lively interest in issues of science and religion during the opening third of the century and the attempt to transcend the Victorian impasse had given way to a less favourable atmosphere by the late 1930s. Increasing politicization and the rise of a new generation of scientists with different agendas led to a greater polarization of positions and a lowering of interest in the topic. Although the discussion of science and religion received a further boost in the postwar period, largely through Charles Coulson's writings, it has regained prominence only during the past few years. The other book under review reflects this trend.

As a molecular immunologist and committed Christian, Denis Alexander is troubled by two popular prejudices of our age. One is the opposition to science (which has sometimes been promulgated in the name of religion); the other is the assumption that science and religion are locked in necessary conflict (a belief that is often advanced in the name of science). To counteract both prejudices, Alexander has written an introductory and wide-ranging text that is intended to encourage the reader to adopt a more tolerant position, particularly on the issue of science and religion, on which atheists such as Richard Dawkins and Peter Atkins have grabbed the public's attention.

To engage this topic, Alexander has to clear the undergrowth by introducing an extensive range of issues that concern both scientific knowledge and religious knowledge (as opposed to belief). Although he acknowledges the role of social factors, he adopts a critical realist stance towards science, rejecting not only the dogmatic image of science that is often conveyed to the public, but also the threat of relativism. On this and other epistemological issues, he conceives close parallels between science and Christianity. Although some of these correspondences are more convincing than others, they not only refute the much-vaunted conflict thesis but also indicate how science and religion can be located in the same epistemological frame.

Alexander also insists that the theory of 